\title{
A RELAÇÃO ENTRE EMPRESA E FAMÍLIA NO PARANÁ: O CASO DO GRUPO THÁ ${ }^{1}$
}

\author{
Natália Cristina Granato
}

- Enviado em 15/04/2016

- Aprovado em 25/05/2016

\section{RESUMO}

O presente artigo procura discutir a relação entre as atividades empresariais e a gestão familiar tendo como referência a Construtora Thá. Presente no ramo da construção civil desde 1895, a Thá, ao longo de sua história, desenvolveu-se com a economia curitibana e paranaense, chegando à sua quarta geração como uma das principais construtoras e incorporadoras do Paraná. O seu pioneiro, o imigrante italiano Mauricio Thá, transmitiu seus negócios às gerações posteriores, sendo administrada majoritariamente por membros da família no decorrer do século XX. No início dos anos 2000, tal panorama se modificou. Buscaremos, neste artigo, ilustrar as fases desta empresa de construção civil e arquitetura com o desenvolvimento econômico do Paraná, relacionando, brevemente, com as questões da imigração italiana, o empreendedorismo e os negócios familiares.

Palavras-chave: Empresa Familiar. Paraná. Construção Civil.

\section{INTRODUÇÃO}

A história empresarial no Paraná possuiu como característica a contribuição dos imigrantes no desenvolvimento de capitais locais. Empresas familiares se destacavam nesse contexto. No presente trabalho, destacaremos a presença da família imigrante italiana "Thá" no processo de urbanização de Curitiba. A Construtora chegou à receita bruta de 80 milhões em 2005, sendo a

\footnotetext{
${ }^{1}$ Artigo apresentado à disciplina HSO756 - Tópicos especiais em Sociologia Política II, ministrada pelo Prof. Dr. Ricardo Costa de Oliveira no segundo semestre de 2015.

${ }^{2}$ Graduada em Ciências Sociais pela Universidade Federal do Paraná (Bacharelado e Licenciatura). Mestra em Sociologia pela Universidade Federal do Paraná. Endereço eletrônico: nataliagranato@ hotmail.com.
} 
maior construtora e incorporadora do Paraná (CONSTRUÇÃO MERCADO, Construtoras familiares resistem ao tempo em nome da tradição, Edição 59, junho de 2006) no ano de 2006. Atuando no Paraná desde 1895, a construtora Thá é a mais antiga empresa do ramo da construção civil. No presente artigo $^{3}$, iremos contextualizar brevemente a relação entre a imigração e o desenvolvimento econômico do Paraná, do final do século XIX até o século XX. No segundo momento, visualizaremos a trajetória da Construtora Thá no Paraná, destacando quais eram os membros da família comandando a empresa, quais eram as suas atividades políticas e sociais no decorrer do século XX e como a empresa se organiza no início dos anos 2000.

\section{A IMIGRAÇÃO ITALIANA E O DESENVOLVIMENTO DA ECONOMIA PARANAENSE}

Políticas governamentais em prol da imigração surgiram no Brasil em meados do século XIX para o atendimento da demanda por mão-de-obra para a agricultura, especialmente no cultivo do café (BALHANA, 1987, p.123). Os imigrantes já estavam começando a inserção no comércio, no artesanato e na indústria no período imperial, com "progressiva participação nos quadros empresariais" brasileiros (BALHANA, 1987, p.130). Conforme aponta Ricardo Costa de Oliveira, “ o sucesso dos imigrantes relacionava-se à rapidez e velocidade com que se adaptavam à sociedade $\mathrm{e}$ à cultura tradicional brasileira" (OLIVEIRA, 2000, p.113).

Os imigrantes europeus foram atraídos principalmente para a região Sul do país, que oferecia vantagens como a possibilidade da aquisição de terras e o clima ameno, parecido com as regiões de origem, o que permitia o cultivo de produtos que os mesmos já estavam acostumados a produzir (CARNIERI, 2013, p.40).

Altiva Balhana (1987, p.124) aponta que o Paraná estava interessado em desenvolver uma política imigratória adaptada às características locais desde meados de sua emancipação político, com a proposição do desenvolvimento de uma "agricultura de abastecimento". As colônias

\footnotetext{
${ }^{3} \mathrm{O}$ presente artigo foi apresentado como trabalho final da disciplina Tópicos Especiais em Sociologia Política II, ministrada pelo Prof. Dr. Ricardo Costa de Oliveira, ofertada pelo Programa de Pós-Graduação em Sociologia da Universidade Federal do Paraná no segundo semestre de 2015.
} 
agrícolas que surgiram nesse contexto se localizavam "nos arredores dos centros urbanos, com objetivo de colocar sua produção junto aos mercados consumidores" (BALHANA, 1987, p.124).

O autor Ricardo Costa de Oliveira assinala que o incentivo à imigração europeia no Paraná foi possibilitado também pela crise da escravidão paranaense, que assistiu à venda de um grande número de escravos para o estado de São Paulo, e o "aburguesamento da classe dominante" ervateira, que modernizou suas técnicas de produção (OLIVEIRA, 2000, p.108).

O incremento da urbanização se desenvolveu paralelamente ao processo de imigração. Segundo Dennison de Oliveira, o estabelecimento dos povos europeus no território intensificou o mercado local e os bens de consumo não-duráveis, ao mesmo tempo em que ofereceu mão-de-obra para o "nascente mercado de trabalho urbano e industrial" (OLIVEIRA, 2002, p.24), possibilitado pelo processo industrial de beneficiamento e comercialização da erva-mate.

A imigração italiana para diversos países do mundo começou por volta de 1869. Desde então, aproximadamente 20 milhões de italianos se dirigiram a países como os Estados Unidos, Brasil e Argentina, números registrados até 1970. Entre meados do século XIX e 1914, a imigração italiana atingiu "mais de um terço da imigração total para o Brasil" (BALHANA, 1987, p.122).

No Paraná, a imigração italiana começou a partir de 1875, a maioria com procedência de Veneto, de Vicenza de Trentino, de Abruzzo, da Basilicata e do Tirol (MARTINS, 1941, p.176). Um desses imigrantes italianos foi Maurício (ou Maurizio) Thá, fundador da construtora mais antiga da capital paranaense, a empresa "Maurício Thá Constructor", iniciou suas atividades em 1895. Thá era especialista em acabamentos e ornatos de fachadas (EXAME, Com os pés no chão, 23 jun.2003). Entre suas obras, destacam-se o antigo Palácio do Governo, na Rua Barão do Rio Branco, em Curitiba, o Palácio Rio Branco, antigo prédio da Assembleia Legislativa, também em Curitiba, o Moinho Matarazzo, em Antonina, o Mercado Municipal e o Santuário de Paranaguá, além das instalações hidráulicas e de esgoto nesta cidade, a estrada de ferro Ponta Grossa- Porto União, entre outras (DIÁRIO DO PARANÁ, Condições para o desenvolvimento da Indústria de Construções Civis, 06 nov.1955, p.22). A construtora Thá iniciou suas atividades em face do desenvolvimento econômico no Paraná, com a significativa contribuição dos imigrantes. As 
imagens a seguir ilustram algumas destas primeiras construções empreendidas pela Construtora Thá:

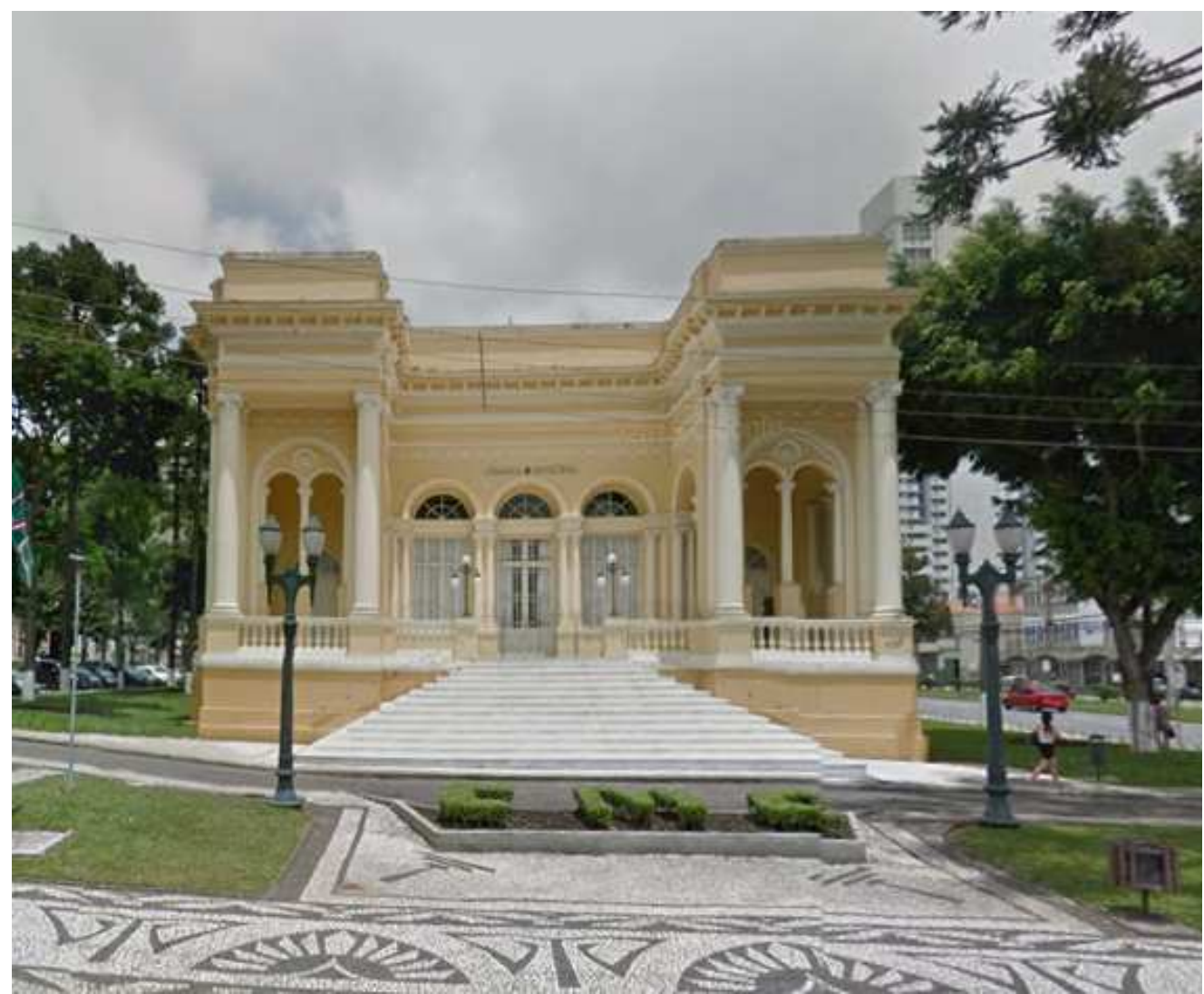

Antigo prédio da Assembleia Legislativa do Paraná, atual Câmara dos Vereadores de Curitiba Crédito da Imagem: Google Maps

Acima, visualizamos o antigo prédio da Assembleia Legislativa do Paraná, atual Câmara dos Vereadores de Curitiba, localizado entre a Avenida Visconde de Guarapuava e a Rua Barão do Rio Branco, na região central de Curitiba. A imagem a seguir mostra a antiga sede do Palácio do Governo, hoje compreende as instalações do Museu da Imagem e do Som (MIS), localizado na Rua Barão do Rio Branco, n³95, também localizado no Centro de Curitiba: 


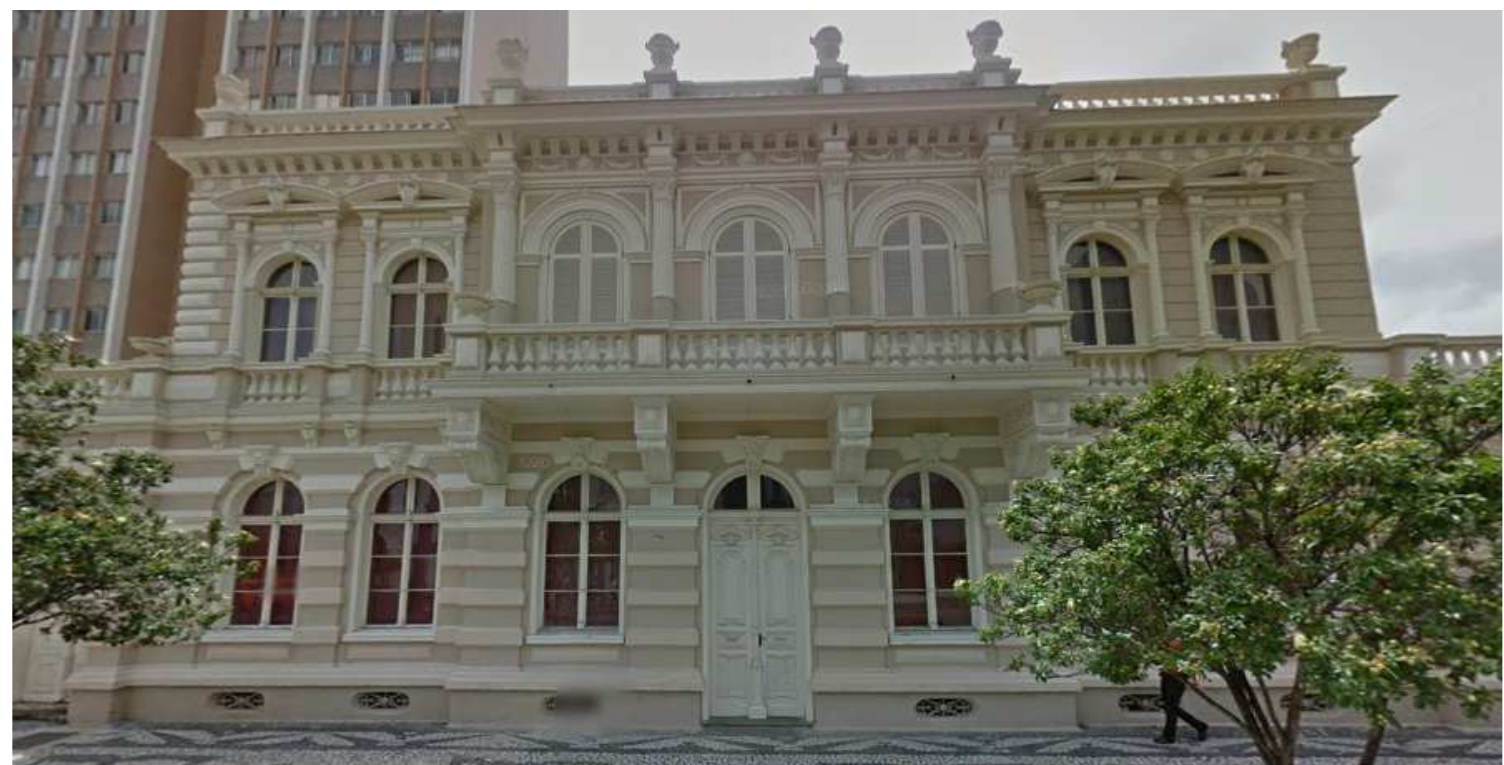

Antiga sede do Palácio do Governo, hoje compreende as instalações do Museu da Imagem e do Som (MIS) Crédito da Imagem: Google Maps

O desenvolvimento econômico no Paraná no início do século XX se fez presente também no litoral do estado. As indústrias Matarazzo se instalaram em Antonina por volta de 1910 e alavancaram o seu desenvolvimento local e empregatício por cinco décadas posteriores. A cidade foi contemplada com a instalação do primeiro porto particular do país (GAZETA DO POVO, Complexo Matarazzo é área de conservação, 28. Nov. 2011, caderno Vida e Cidadania). Próximo ao porto, localizavam-se os moinhos de trigo, sal, açúcar e erva mate da indústria. Trata-se de uma família da imigração italiana que desenvolveu seus negócios no Brasil, construindo um império industrial no século XX. Atualmente, as ruínas do Complexo Industrial Matarazzo estão localizadas na Avenida Conde Matarazzo, Antonina, ao lado do Porto de Antonina. 


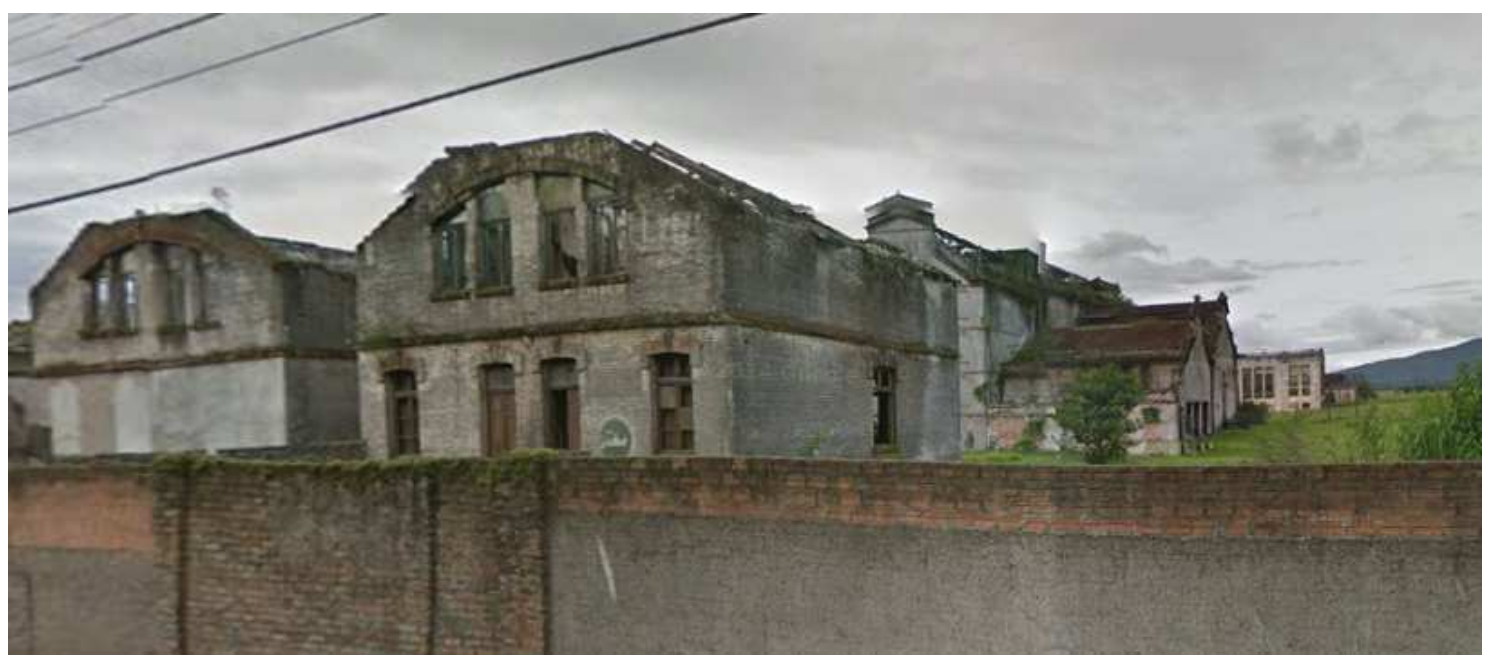

Ruínas do Complexo Industrial Matarazzo estão localizadas em Antonina Crédito da Imagem: Google Maps

Pesquisas sobre a relação entre a imigração italiana e o desenvolvimento econômico e empresarial local fizeram parte das reflexões de historiadores da Universidade Federal do Paraná. Na pesquisa de Altiva Balhana sobre a imigração italiana no Paraná, destaca-se o grande número de empresários italianos na Primeira República, a partir de um levantamento de informações obtidas através dos arquivos da Junta Comercial do Paraná entre 1890 e 1929. Nesse período, suas empresas estavam presentes em 27 dos 51 municípios do interior do estado, além de sua significativa presença em Curitiba (BALHANA, 1987, p.134).

No caso da construção civil, os italianos e seus descendentes correspondiam $15 \%$ do total de empresários (somando-se a $25 \%$ de brasileiros e $60 \%$ de outras nacionalidades), segundo a mesma pesquisa de Altiva Balhana. A grande participação dos imigrantes no desenvolvimento do capitalismo no Brasil deve-se às condições de classe que os mesmos já possuíam na Europa. Ricardo Costa de Oliveira, citando Warren Dean, aponta que os imigrantes, em sua maioria, “já possuíam experiências no comércio, na manufatura e detinham conhecimentos técnicos" (OLIVEIRA, 2000, p.110), ou seja, recorrentemente faziam parte da classe média urbana nos seus respectivos países de origem. 


\section{A COSNTRUÇÃo CIVIL NO PARANÁ E O GRUPO EMPRESARIAL THÁ}

Entre 1870 e 1930, a economia da erva-mate vivenciou o seu terceiro ciclo e expansão, que representou um avanço efetivo no preparo industrial do mate, modernizando-se as técnicas de colheita e beneficiamento com um modelo que preservasse a planta aumentando a racionalidade da produção (VANALI, 2013, p.18). Ana Vanali (2013) destaca que esta era uma fração de classe burguesa em ascensão econômica e política neste período, sendo a erva-mate o principal produto de exportação do Paraná. Com a economia da erva-mate em expansão, os barões do principal produto da economia paranaense nos fins do século XIX e início do século XX mandavam construir seus "palacetes" para moradia. O "Palacete do Batel" foi construído a pedido de Ildefonso Rocha, entre os anos de 1912 e 1914, empreendida por Maurício Thá. A inspiração italiana na arquitetura e na decoração dos palacetes deviam-se às viagens feitas pelos Barões e à nacionalidade dos arquitetos (GAZETA DO POVO, As casas remanescentes da Curitiba dos barões da erva-mate, 03 nov. 2015, Caderno Haus). Um dos principais arquitetos da cidade era o italiano Ernesto Guaita (SOUZA; LYRA, 1994, p.49).

Em 1931, a empresa criada por Maurício Thá se tornou as "Irmãos Thá", sob a direção de seus três filhos Eduardo Thá, Mikare Thá e Reinaldo Thá (DIÁRIO DO PARANÁ, Irmãos Thá faz $75^{\circ}$ aniversário de atividades, 13 set.1970. p.9).

No período pós-segunda guerra mundial, a empresa assistiu mais outro surto de crescimento urbano, especialmente vertical, com grande número de construções de prédios em Curitiba. No início da década de 1950, a construtora Thá foi responsável pela edificação de grandes prédios na região central. São eles: Edifício Ana Cristina Canet, na Praça Osório, de propriedade de Jayme Canet Júnior; Edifício Imaculada Conceição, de propriedade do industrial e deputado João Chede; Edifício Santa Maria, na Praça Zacarias; Edifício Santa Adélia, na Rua Emiliano Perneta, Edifício Ana Zulmira, na Rua Comendador Araújo, também de propriedade de Jayme Canet Júnior; Edifício Ivahy, na Rua Serro Azul, Edifício do Banco Nacional do Comércio, na Marechal Deodoro, Edifício Bettega, na Monsenhor Celso, entre outros (DIÁRIO DO PARANÁ, Entregaram em 25 anos milhares de residenciais aos proprietários, 02 nov.1956, p.11). Visualizaremos a seguir alguns 
prédios localizados no Centro de Curitiba construídos pela Thá. O primeiro corresponde ao Edifício Ana Cristina Canet, localizado na Praça Osório, n45:

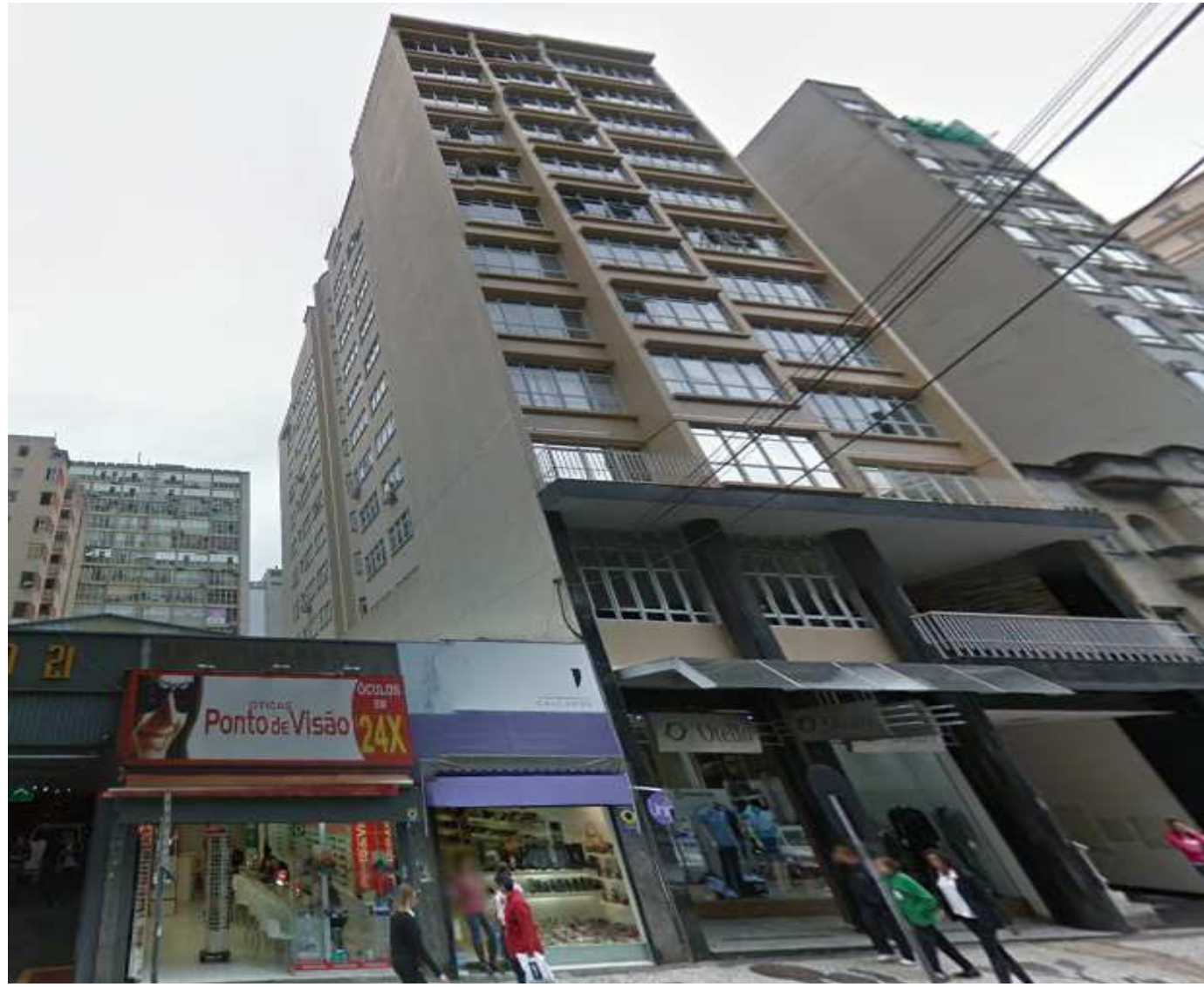

Edifício Ana Cristina Canet, localizado na Praça Osório

Crédito da Imagem: Google Maps

Visualizaremos a seguir o Edifício do Banco Nacional do Comércio, localizado na Rua Monsenhor Celso, $\mathrm{n}^{\circ}$ 154, esquina com a Rua Marechal Deodoro no centro de Curitiba: 


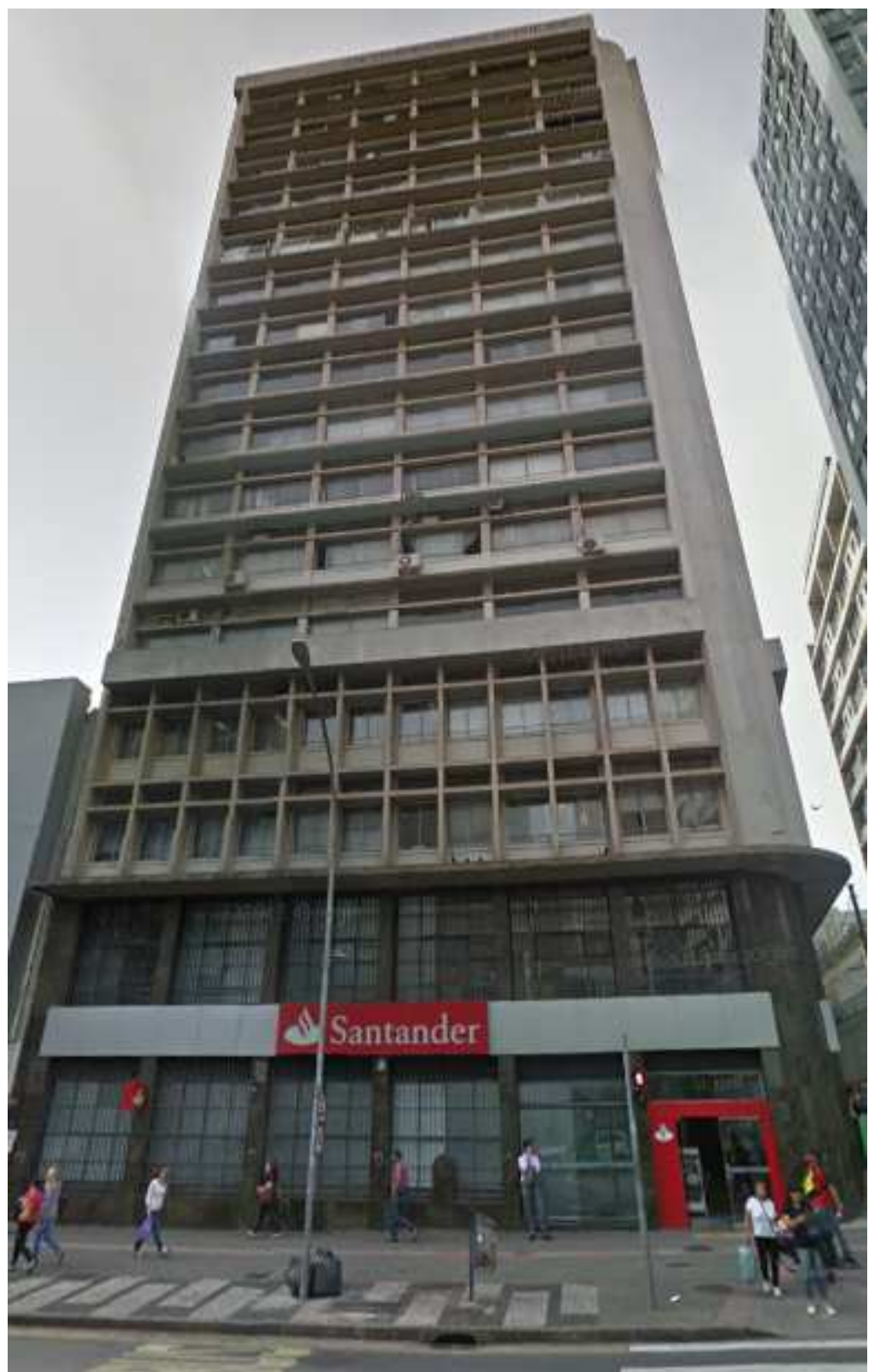

Edifício do Banco Nacional do Comércio, localizado na Rua Monsenhor Celso, Crédito da Imagem: Google Maps

Na década de 1950, a Construtora Thá era administrada pelo superintendente Eduardo Thá, pelo diretor comercial Mikare Thá e pelo diretor industrial Orestes Thá, tendo como diretores técnicos Armando Miguel Matte e Eduardo Thá Júnior (DIÁRIO DO PARANÁ, Irmãos Thá S.A. 
Comemoram cinco lustros de trabalho pelo engrandecimento do Paraná, 04 nov.1956, p.16). Os irmãos pertenciam à segunda geração familiar na direção da empresa. Os mesmos também foram construtores do estádio Dorival de Brito, que recepcionou a copa de 1950 (EXAME, Com os pés no chão, 23 jun.2003). Orestes Thá foi nomeado pelo governo do estado como membro do Conselho á foi nomeado pelo governo do estado como membro do Conselho Regional de Desportos do Paraná, e seu nome foi dado ao Estádio Esporte Clube Água Verde, em Curitiba (ALMEIDA, 1968, p.297). Suas atividades filantrópicas na área dos esportes são demonstradas por Dino Almeida:

\begin{abstract}
"A versatilidade humana não tem limites. Principalmente quando existe, na personalidade, formação humanística integral, assim é que um engenheiro pode, também, dedicar-se a atividades filantrópicas, além daquelas que a sua profissão o obriga. A dupla personalidade do engenheiro e do filantropo não se chocariam nem sofreriam qualquer alteração, se o gosto individual derivasse para o setor esportivo. O homem pode ser, portanto, aquilo que desejar, fazendo o que sua vontade, seu gosto ou sua formação determinam. Tal é, em Curitiba, o caso de Orestes Thá, industrial que se dedica, como seus irmãos, a atividades no campo da engenharia civil, levantando edifícios, participando de sociedades e liderando movimentos esportivos" (ALMEIDA, 1968, p.297)
\end{abstract}

Orestes Thá também era membro da Fundação de Recuperação do Indigente e do Rotary Clube de Curitiba (ALMEIDA,1968, p.297). Também foi presidente do clube de Futebol Pinheiros de 1948 a 1957 (PLACAR MAGAZINE, Pequeno grande time do Paraná, 13 abr.1987, p.38).

A influência da família se fez presente na política paranaense também. Em 1960, os irmãos Thá apoiaram a campanha de Ney Braga para o governo do estado (DIÁRIO DO PARANÁ, Ao povo do Paraná, 17 jan.1960 p.10), e Eduardo Thá Júnior foi nomeado integrante do Conselho Fiscal da recém-criada TELEPAR, no governo Ney Braga (DIÁRIO DO PARANÁ, Telecomunicações vão avançar meio século no Paraná: TELEPAR, 07 dez.1963, p.6).

A Construtora Thá expandiu seus negócios com a venda de materiais de construção e imobiliária. A mesma também foi responsável pela construção do Aeroporto Afonso Pena em São José dos Pinhais, e a Escola de Agronomia e Veterinária, em Curitiba (DIÁRIO DO PARANÁ, Oitenta anos de Irmãos Thá, 19 dez.1975, p.19). 
A seguir, visualizaremos a vista aérea do Aeroporto Internacional Afonso Pena, construído pela Thá:

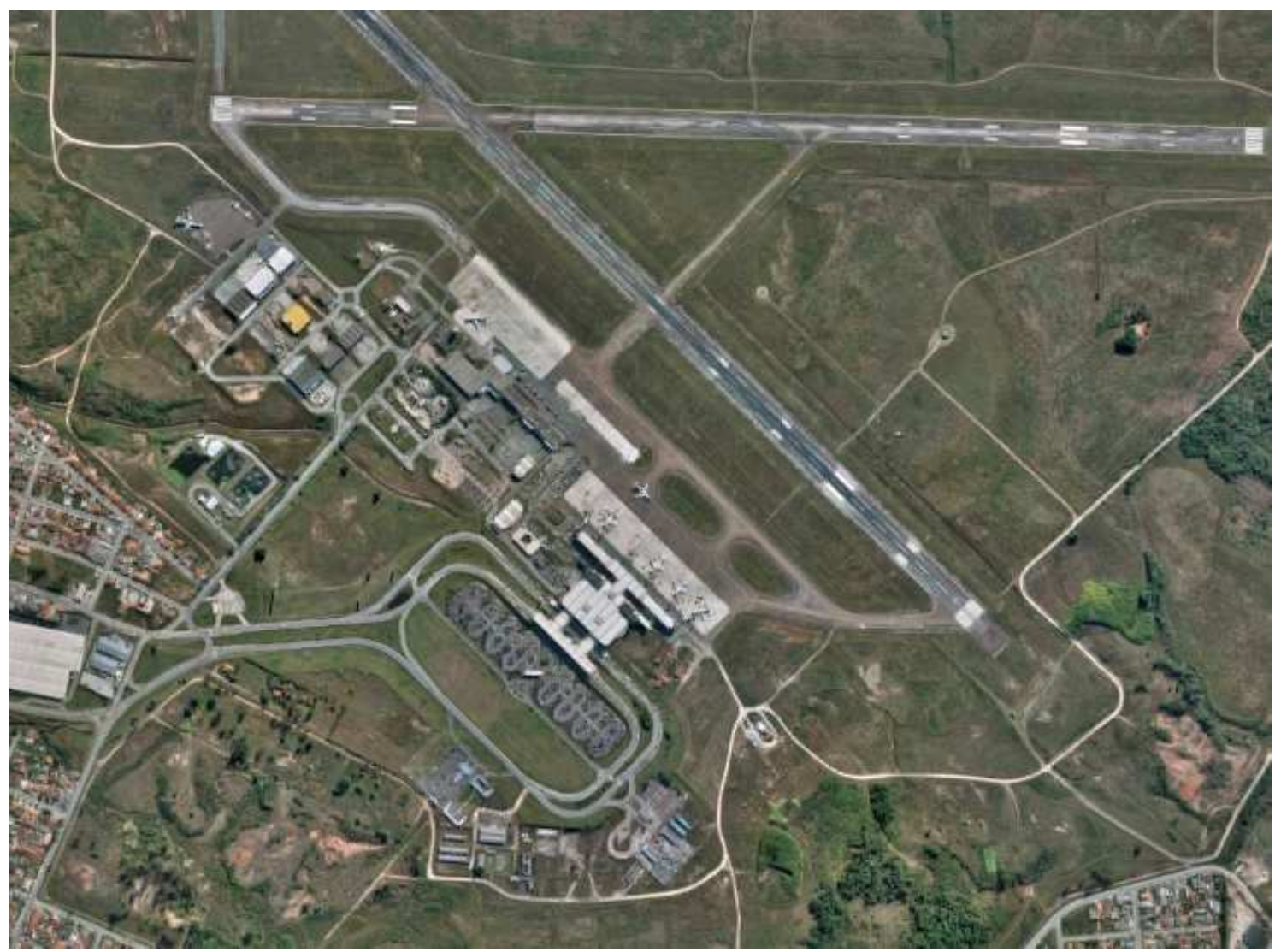

Vista aérea do Aeroporto Internacional Afonso Pena Crédito da Imagem: Google Maps

O pioneiro Maurício Thá teve três filhos e doze netos, e a construtora chega à sua terceira geração e quarta geração, multiplicando o número de bisnetos e acionistas. Em 1982, uma crise financeira na empresa ocasionou no corte de três dos quatro executivos herdeiros da empresa, fazendo com que o número de sócios familiares diminuísse com a venda de ações da empresa. (CONSTRUÇÃO MERCADO, Construtoras familiares resistem ao tempo em nome da tradição, Edição 59, junho de 2006). 
Ao longo das décadas, a Construtora Thá esteve presente nos grandes empreendimentos imobiliários na região de Curitiba. Ela foi uma das construtoras dos galpões industriais da Audi e Volkswagen em São José dos Pinhais, nos anos 1990, tendo como clientes grandes empresas como o Carrefour, Sonae, Sendas, Wal-Mart e Pão de Açúcar (EXAME, Com os pés no chão, 23 jun.2003). O negócio continuou familiar, tendo como presidente Alberto Acioly Veiga Filho, bisneto de Maurício Thá (EXAME, Com os pés no chão, 23 jun.2003).

A Thá permaneceu uma empresa familiar até a terceira geração, rompendo com essa lógica na quarta geração.

Em 2006, Alberto Acioly Veiga colocou em prática um velho projeto de contratar alguém fora da família para ser o presidente da Construtora Thá, escolhendo Francisco Paschoal, executivo com experiência em multinacionais e companhias familiares. Somente Alberto Acioly Veiga e o engenheiro Roberto Thá permanecem na empresa como executivos, pertencentes à família do fundador (CONSTRUÇÃO MERCADO, Construtoras familiares resistem ao tempo em nome da tradição, Edição 59, junho de 2006)

Recentemente, o controle acionário do Grupo Thá foi vendido para o fundo de investimentos Equity International, pertencente ao investidor norte-americano Sam Zell (GAZETA DO POVO, Grupo Thá é vendido para fundo americano, 03 jan.2012), com o objetivo de expandir os negócios e se tornar uma potência do ramo na Região Sul, logrando êxito desde então (EXAME, Thá quer ser potência regional em incorporação, 06 out.2014).

\section{CONSIDERAÇÕES FINAIS}

O presente artigo buscou relacionar a imigração italiana no Paraná e o desenvolvimento econômico através das atividades empresariais familiares estabelecidas pela Construtora Thá na sua atuação centenária no estado. Visualizamos o ciclo econômico de apogeu da erva-mate registrado no final do século XIX e início do XX, e a atuação da empresa nas construções de palacetes para os "barões ervateiros" e os edifícios governamentais do início do período republicano. Por volta da 
década de 1930, a empresa assistiu à ascensão de sua segunda geração, incrementando os seus negócios com o surto do crescimento urbano de Curitiba e a construção de prédios na sua região central.

A segunda geração de descendentes da família Thá manteve os negócios no âmbito familiar, obtendo uma relativa inserção na política paranaense e nas atividades beneficentes, e sociais, principalmente às que envolviam o esporte. A empresa manteve um bom relacionamento com os governos, sendo a responsável pela construção de grandes obras como o Aeroporto Afonso Pena.

A terceira e a quarta geração de descendentes de Maurício Thá correspondem a uma multiplicidade de herdeiros e acionistas que neutralizaram a ação familiar nos negócios empresariais, tornando a construtora internacionalizada, se adequando, em grande parte, às características do capitalismo contemporâneo. A história social desta empresa confunde-se com o próprio desenvolvimento econômico do Paraná no século XX. Espera-se que este trabalho contribua para estudos sobre a relação entre a imigração e o desenvolvimento econômico no Paraná, ainda muito incipientes na produção acadêmica do estado.

\section{REFERÊNCIAS}

ALMEIDA, Dino. Bandeirantes do Progresso. Curitiba: Alfa Empreendimentos do Paraná Ltda e Papelaria Universal Ltda, 1968.

BALHANA, Altiva Pilatti. "Italianos no Paraná”. In: DE BONI, Luis (org.). A presença italiana no Brasil. Porto Alegre: Escola Superior de Teologia e Fondazione Giovanni Agnelli, 1987.

CARNIERI, Christopher Augusto. A italianidade em movimento: travessias e olhares. Dissertação. Mestrado em Antropologia Social. Curitiba, Universidade Federal do Paraná, 2013.

MARTINS, Romário. Quantos somos e quem somos: Dados para a história e a estatística do povoamento no Paraná. Curitiba: Empreza Gráfica Paranaense, 1941. 
OLIVEIRA, Dennison de. Industrialização e Urbanização no Paraná. Curitiba: SEED, 2002.

OLIVEIRA, Ricardo Costa de. O silêncio das genealogias: classe dominante e estado no Paraná (1853-1930). Tese. Doutorado em Ciências Sociais. Universidade Estadual de Campinas, 2000.

SOUZA, Alcídio Mafra de; LYRA, Cyro Corrêa. Guia de bens tombados. Rio de Janeiro: Expressão e Cultura, 1994.

VANALI, Ana Crhistina. A Erva-mate e a política paranaense: análise da legislação provincial para a economia ervateira (1854-1889). Curitiba: Instituto Memória, 2013.

\section{IMAGENS}

GOOGLE MAPS. Disponível em: https://www.google.com.br/maps. Acesso em 13/04/16.

\section{PERIÓDICOS}

CONSTRUÇÃO MERCADO, Construtoras familiares resistem ao tempo em nome da tradição, Edição 59, junho de 2006. Disponível em: http://construcaomercado.pini.com.br/negociosincorporacao construcao/59/artigo282155-1.aspx Acesso em 25/02/16

DIÁRIO DO PARANÁ, Condições para o desenvolvimento da Indústria de Construções Civis, 06 nov.1955, p.22

DIÁRIO DO PARANÁ, Entregaram em 25 anos milhares de residenciais aos proprietários, 02 nov.1956, p.11

DIÁRIO DO PARANÁ, Irmãos Thá S.A. Comemoram cinco lustros de trabalho pelo engrandecimento do Paraná, 04 nov.1956, p.16

DIÁRIO DO PARANÁ, Ao povo do Paraná, 17 jan.1960 p.10

DIÁRIO DO PARANÁ, Telecomunicações vão avançar meio século no Paraná: TELEPAR, 07 dez.1963, p.6 
DIÁRIO DO PARANÁ, Irmãos Thá faz 75 aniversário de atividades, 13 set.1970. p.9

DIÁRIO DO PARANÁ, Oitenta anos de Irmãos Thá, 19 dez.1975, p.19

EXAME, Com os pés no chão, 23 jun.2003. Disponível em: http://exame.abril.com.br/revistaexame/edicoes/795/noticias/com-os-pes-no-chao-m0052148. Acesso em 20/02/16

EXAME, Thá quer ser potência regional em incorporação, 06 out.2014. Disponível em: http://exame.abril.com.br/negocios/noticias/tha-quer-ser-potencia-regional-em-incorporacao Acesso em $21 / 02 / 16$

GAZETA DO POVO, Complexo Matarazzo é área de conservação, 28. Nov. 2011, caderno Vida e Cidadania. Disponível em: http://www.gazetadopovo.com.br/vida-ecidadania/especiais/litoral/complexo-matarazzo-e-area-de-conservacaoc59cok93fdhqntp1ep0i6d74e . Acesso em 12/03/16

GAZETA DO POVO, Grupo Thá é vendido para fundo americano, 03 jan.2012. Disponível em: http://www.gazetadopovo.com.br/economia/grupo-tha-e-vendido-para-fundo-americano734nbxvnyj0wscahv9m060rwu Acesso em 12/02/16

GAZETA DO POVO, As casas remanescentes da Curitiba dos barões da erva-mate, 03 nov. 2015, Caderno Haus, por Annalice Del Vecchio Disponível em: http://www.gazetadopovo.com.br/haus/estilo-cultura/as-casas-dos-baroes-curitibanos/ Acesso em $21 / 02 / 16$ 


\title{
THE RELATION BETWEEN THE COMPANY AND FAMILY IN PARANÁ: CASE GROUP THÁ
}

\begin{abstract}
This article discusses the relationship between business activities and family management with reference to the Construction Thá. Present in the construction industry since 1895, Thá over its history, developed with Curitiba and state economy, reaching its fourth generation as one of the leading builders and developers of Parana. Their pioneering, the Italian immigrant Mauricio Thá, conveyed their business to subsequent generations, and mostly managed by family members during the twentieth century. In the early 2000s, this panorama has changed. We seek in this article illustrate the stages of this construction company and architecture with the economic development of Paraná, relating briefly with the issues of the Italian immigration, entrepreneurship and family business.
\end{abstract}

Key-words: Family business. Paraná. Construction. 